\title{
An Empirical Case Study of Knowledge Transfer within an Organization
}

\author{
Sangeetha Kodam, Alan Eardley, and Rajnandu Bolli
}

\begin{abstract}
The paper focuses on how the knowledge is being transferred from peer to peer in an organization. Knowledge can be transferred in a number of ways. Knowledge is being considered as the essential resource by most of the organizations. Knowledge gives the richness to the organization, has to be managed to fulfill its aims and targets. Knowledge of individual / organization can be improved by transferring it. We also emphasize the knowledge transformation between entities to discover the central aspect of knowledge transfer by considering two different IT companies as a case study.
\end{abstract}

Index Terms-Explicit knowledge, knowledge transfer, knowledge management frameworks (KMFs), tacit knowledge.

\section{INTRODUCTION}

The organization constitutes the knowledge of employee's, system's and the organization's. This knowledge has to be managed to enhance and to win on our competitors. Knowledge can be captured, shared, collaborated, re-used and socialized. Almost in every organization knowledge is considered as tactically important resource and learning as important capability for business organization. Many organizations began variety of knowledge management projects and programs. Knowledge is viewed as their most valuable and strategic by business organizations [1]. Knowledge Management depends on business environment in order to globalize and to face fierce competition. It is essential for an organization to develop a knowledge management system which is simple, moderate and advanced. Two sorts of knowledge can be found in organizations- Explicit and Tacit knowledge.

1) Explicit Knowledge: Explicit Knowledge is the knowledge that has been articulated. It can be expressed orally or written down or documented using information technology tools. The knowledge found through books, diagrams, case studies, documents, and libraries, chapters from the book, web portals and project reports are explicit. It lives in people's head and books. Explicit Knowledge shows what we know or what knowledge is it. It is believed that in any organization only $20 \%$ of explicit knowledge exists.

2) Tacit Knowledge: Tacit knowledge or implicit knowledge lives in people's practices. It is harder to grasp as it is the experience of other's. It is resided on people's head.

Manuscript received February 19, 2016; revised June 1, 2016.

Sangeetha Kodam is with Staffordshire University, UK (e-mail: sangeethanetha@gmail.com).

Alan Eardley is with the Faculty of Computing Engineering and Sciences at Staffordshire University, UK (e-mail: w.a.eardley@staffs.ac.uk).

Rajnandu Bolli is with Cyberheights Technologies, India (e-mail: rajnandu.b@gmail.com)
$80 \%$ of the knowledge in the organization that is present within is tacit. It deals in helping in knowing how to respond to a condition on an action. It is inferred from the knowledge worker by business analyst or knowledge engineer. Tacit knowledge can be used for the basis for a judgment and informed action. Interpreting the specific data can be understood by tacit knowledge and can be used as explicit knowledge in future. Identifying the buying or shopping habits of a customer in a particular season, this helps in improving the sales by knowing and taking customer requests as patterns. Diagnosis of the patient illness is another example where tacit knowledge applied; the patient can be treated once the patient's health condition is studied. Once the outcome is known it is a straight way to recognize the criteria used to select the response to a situation or an issue, which can be turned into explicit knowledge. So, knowledge management is essential to an organization as it does not depend on individuals and their capability. There is no common framework to be used by the organization to develop the knowledge. The firm has to follow one of the knowledge management frameworks (KMF). In each framework one aspect is concentrated. There are two types of frameworks (Fig. 1)

Descriptive Frameworks: This framework depicts the behaviour of the knowledge management methodology.

Prescriptive Frameworks: These frameworks illustrate the methodologies to follow in conducting knowledge management.

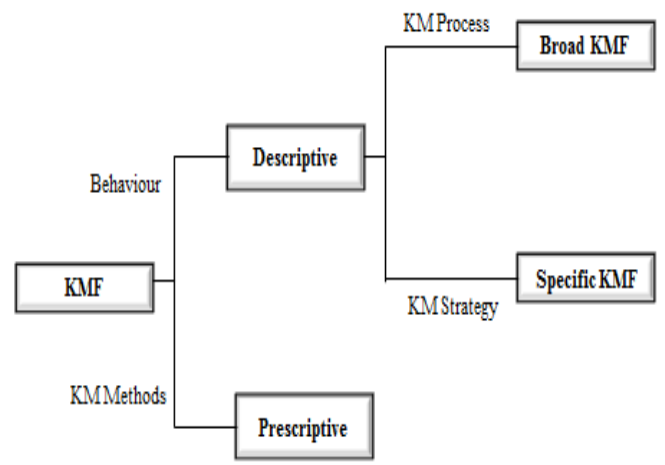

Fig. 1. Knowledge management frameworks.

Few organizations appoint chief knowledge officers (CKOs) and perform knowledge management activities in their organization [2]. Understanding knowledge management is crucial for an organization. Following knowledge management framework helps in growing the company reputation by means of knowledge. An employee's abilities also enhanced with appropriate methodology. Knowledge sharing and transferring improves the richness of the knowledge what the organization holds. 


\section{KNOWLEDGE TRANSFER}

Knowledge transfer is not a linear development which can be observed by an administrator. Knowledge can be modified when it is shared with others. Knowledge transfer can be considered as simple as discussing even on a dining table during the lunch (at organization). In the context of an organization the management has to facilitate with the team where the internal and external experts, local researchers are involved, so the trainer or the fresher can gain knowledge from them by discussing or communicating with them. Different authors, researchers identified the knowledge as an important tool and recognized the significance of knowledge transfer between employees within the organization. Knowledge transfer is based on the trust. The entities that share/transfer the knowledge need to have a good relationship [3], [4]. This inter communication effects the success rate of the knowledge transfer. David [3] identified the knowledge crating and sharing as an essential key to organization for their progress. He considered four components - idea creation, idea sharing, idea evaluation, idea discussion and idea adoption for knowledge transfer. Szulanski's model of knowledge transfer is used to analyze the difficulty in transferring the knowledge within organization. Four factors that affect the internal effectiveness (or stickiness) for knowledge transfer:

1) Characteristics of knowledge transfer

2) Characteristics of knowledge source

3) Characteristics of knowledge recipient

4) Characteristics of the context

\section{Case Study of KnOWledge Transfer Technique at DIFFERENT ORGANIZATION}

\section{A. Case Study 1}

Knowledge transfer at Cyber Heights Software Technologies:

This organization progress the work as client - centric approach. Knowledge sharing begins in the early stages of software development.

Phase 1. In this initial stage, two or three members of the team meet the client (or client's office) to assimilate the requirements for the software. This team probably consists of one technical person and the business analyst. On one hand the Technical person identifies the technology/software being used by that client and their satisfaction. On the other hand, market people attempt to recognize the constraints from the customer like time and budget. Requirements are accumulated in this phase.

Phase 2. After gathering and understanding the client's requirement, organization selects team members to be assigned and work on that particular project. A formal meeting is conducted where the members (who gathered the requirements) illustrate the requirements in detail. Anyone in the team can share their idea for a possible solution for the problem. Which technologies should be used, execution time and budget identified by the end of the meeting. The suitable idea may come up with either their explicit or implicit knowledge. But, most of the time, it is being selected from one's tacit knowledge. Then the pros and cons of the software can be identified using earlier software documents or tacit knowledge gained from similar projects.

Phase 3. Once the project development process is ready should be approved by high authority. And all the team members who involved in this development maintains confidentiality (sometimes requested within organization also).

Phase 4. When implementing the product, informal meetings may take place to ensure the quality of the product. Group discussions take place to know the status of each module in order to accomplish the project in estimated time. At this phase, one's acquaintance gained through the current process can be transferred to the rest to avoid period deferments. Once the entire team is ready for the product released, is now delivered to the customer.

Phase 5. If the product is service-based supporters are assigned for the assistance for the customer; otherwise all the possible future extensions are analyzed and documented.

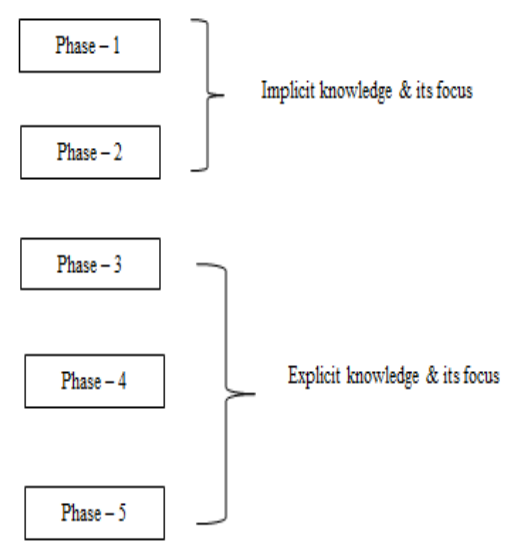

Fig. 2. Knowledge sharing at cyber heights

All the above phases passed by the organization sharing the knowledge (phase-1, 2) and transferring the knowledge (phase-4). When the knowledge is being transferred receiver must understand the sender's context which may lead to the product failure if miscarried.

\section{B. Case Study 2}

Knowledge Transfer Technique in QA team of an International IT company

Stage 1. Idea invention: Innovative people come up with an idea by using their tacit/explicit knowledge.

Stage 2. Idea Discussion: In a formal meeting the innovated idea is explained by the source to the rest of the team members. In this idea sharing time the evaluation of idea may also take place. The consequences of idea development can be anticipated by member's tacit knowledge here. One of the Szulanski's [5] effective factors for knowledge transfer is strictly followed - Proved data. As the sender who presents or shares the knowledge do Noso by their experience (tacit knowledge).

Stage 3. Idea Occupation: Once the knowledge is transferred among the team, the individuals can explore the tacit knowledge on the same by experimenting according to their tacit knowledge. Tacit knowledge is being transformed to others and gains implicit knowledge. The knowledge transferred is experimented and analyzed by the members of 
the team hence enhances their tacit knowledge (Fig. 3).

Stage 4. Once the knowledge is transferred and proved in the team, then the whole practice (solution to a problem) can be articulated in the form of documents. This organization maintains a rich set of documents for future references called "Wiki pages" which are available only on the intranet. In some circumstances, these wiki pages also require the authorization from the author. The other form of documentation includes manuals and user guides for the specified project. Wiki pages give a lot of scope to the newly joined people and to trainee/interns to understand the product development process and gets some idea about the context of the knowledge. This process can also be worked out with other teams (Development team and product).

Stage 5. Trust- is the company's main policy to be followed by all the employees. Individuals are unrestricted to discover their notions and are supported by all available resources. According to my experience as an intern, the knowledge context being shared is very important.

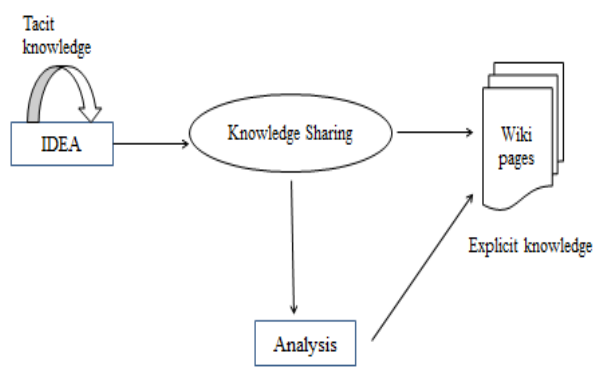

Fig. 3. Knowledge transfer in QA team.

\section{How Much KNOWLEDGE Is TRANSFERRED?}

Knowledge can be transferred in four different modesSocialization (Tacit-Tacit), Externalization (Tacit-Explicit), Combination (Explicit-Tacit), Internalization (Explicit-Explicit).

\section{A. Do the Knowledge Converted into Meaning While Transferring?}

Most companies follow a system for organizing and distributing explicit knowledge [6]. When the data is transferred we can assure that information is transferred but cannot ensure whether the meaning is transferred or not. It is the responsibility of the receiver to understand the meaning of the information.

For example:

Consider, the sender is sending an information "If you miss the deadline you miss your project" to the receiver. It now depends on the receiving unit ability to understand the information transferred and converting it into his knowledge. If Receiver does not know when the deadline is, there is no meaning in it. If he knows the deadline, he probably finishes his task on time as he understands it and don't want to miss the project. Knowledge is the uniquely human capability of making meaning from the information [7].

\section{B. Do the Receiver Understand Exactly as Intended by the Sender?}

Understanding the data (symbols, languages etc.), understanding the context, understanding the process implies learning on the receiver part. Learning turns information into knowledge. The information contains no inherent meaning [7]. When the knowledge is transferred between individuals; it does not replicate the knowledge in the receiving unit. The key element in knowledge transfer is to which extent the receiver understands the knowledge and how effectively using for their operations. According to Sveiby [8], [9] knowledge is dynamic and it is about what we know, where the information is static and independent of the individuals. The Nonaka's [9] case study of 'bread making' strategy is criticized as unrealistic by some researchers. Because, we cannot predict that the apprentice has used her own tacit knowledge and copied the bread making or converted the tacit knowledge of the baker. Information always provokes different meanings in human depending on our interests, feelings, attitudes, sense of relevance. Szulanski's model of knowledge transfer is used to analyze the difficulty in transferring the knowledge within organization. Four factors that affect the internal effectiveness (or stickiness) for knowledge transfer:

1) Characteristics of knowledge transfer

2) Characteristics of knowledge source

3) Characteristics of knowledge recipient

4) Characteristics of the context

Hugh Mackay [10] suggests that it is not important to know what happened to the receiver with information but it should be observed how the information is used by our message; that determines the success in transferring the information. $\mathrm{He}$ also adds it does not matter the meaning we sent rather it's the audience meaning in to message. Conversion of meaning to knowledge completely depends on the individuals. How they want to convert it will take the same form, if they want it to remain as explicit then they don't find the meaning. But if they want the meaning, they will learn and gain knowledge. This helps them to gain some tacit knowledge by the message.

\section{CONCLUSION}

Management Frameworks (KMFs) helps an organization in managing, storing and sharing knowledge [11]. Knowledge transfer enhances the richness of organization technically. Within the firm or external firm, the knowledge should be shared to achieve the top position in today's competitive world. Employees are to be upgraded by sharing knowledge among them or by following one of the knowledge transfer strategies to enhance their ability to work and gain experience. The information can be converted easily into knowledge with learning. So, the organization, members in it has to keep on learning. The context of the message and the ability of the receiver have a high impact on knowledge transfer. I conclude that success rate of knowledge transfer depends on the tacit and explicit knowledge of the receiver and also on the relationship among the entities. It is useless if the receiver does not understand the information, it will be an asset to the organization only if they understand and utilize it properly.

\section{REFERENCES}

[1] M. H. Zack, "Developing a knowledge strategy," California Management Review, vol. 41, no. 3, Spring, pp. 125-145, 1999. 
[2] C.W. Holsapple and K. D. Joshi, "Description and analysis of existing knowledge management frameworks," in Proc. $32^{\text {nd }}$ Hawaii International Conference on System Sciences, 1999.

[3] I. David, "Levine \& April Gilbert managerial practices underlying one piece of the learning organization," Knowledge Transfer, Institute of Industrial Relations.

[4] KTP at QUB Associate Induction Book, Queen's University Belfast.

[5] G. Szulanski, "Exploring international stickiness: Impediments to the transfer of best practices within the firm," Strategic Management Journal, vol. 17, pp. 27-43, 1996.

[6] H. Davies and R. Dermott, "Knowledge management: Summary of lessons learned from their organizations," Using IT to Support Knowledge Management, Houston, TX, 1997.

[7] F. J. Miller, " $\mathrm{I}=0$ (Information has no intrinsic meaning),", Information Research, vol. 8, no. 1, October 2002.

[8] K.-E. Sveiby, The New Organizational Wealth: Managing and Monitoring Knowledge-Based Assets, San Francisco, CA: Barrett, Kohler.

[9] I. Nonaka and H. Takeuchi, The Knowledge-Creating Company: How Japanese Companies Create the Dynamics of Innovation, 1995.

[10] H. Mackay, The Good Listener, Sydney: Pan Macmillan, 1998.

[11] P. J .Sharp, W. A. Eardley, and H. Shah, "Complexity and clarity: The knowledge strategy dilemma-some help from make," Knowledge Management and Innovation, 2010.

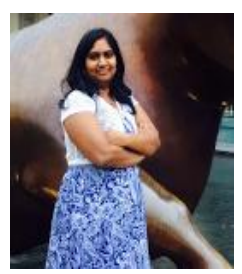

Sangeetha Kodam was born in India in 1985. She attained the master's degree in computer science from Staffordshire University in the U.K. in 2016 and her bachelor's degree in computer science from Jawaharlal Nehru Technical University Hyderabad in the year of 2006. She has the IT industry experience as a test analyst and BCS ISTQB certified tester. Her research interest includes software engineering, cloud computing and knowledge management. Sangeetha has associate membership of British Computer Society and a member of Young Professional Group (YPG) for North Staffordshire Branch.

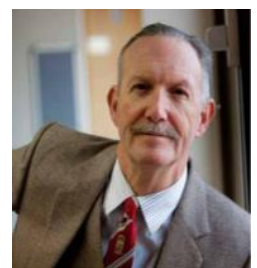

W. Alan Eardley was born in Stoke-on-Trent, England in 1949. Through part-time study as a mature student he obtained a B.A. in business studies with first class honors in 1984 and a master's degree in computer science from Aston University in the U.K. in 1989. His PhD, in strategic information systems from Southampton University in the U.K., supervised by Professor David Avison was awarded in 2001. Alan is professor of enterprise computing in the School of Computing at Staffordshire University in the U.K. and is an adjunct professor at Asia Pacific University of Technology and Innovation in Kuala Lumpur. Professor Eardley researches, publishes and supervises $\mathrm{PhD}$ students in knowledge management and IT strategy and teaches research methods. He is a long standing member of the British Computer Society and a chartered IT practitioner.

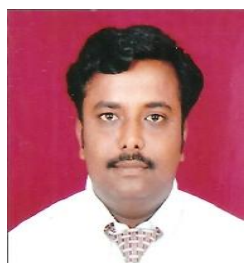

Rajnandu Bolli was born in 1983 and brought up in Hyderabad, India. He obtained a bachelor's degree in electronics and communication engineering from Jawaharlal Nehru Technical University in 2005 and the masters in business administration from Osmania University in the year 2007. Rajnandu currently he is working as a vice president for cyber heights and the co-founder of cyberheights innovation centre. $\mathrm{He}$ was a business developer for the same organization earlier. His research interests are disruptive innovation, computer vision, social computing and digital social innovations. 